\title{
Technological enhancements in the teaching and learning of reflective and creative practice in dance.
}

\section{Introduction}

This paper considers research into applications of technologies in dance in higher education and focuses on practice with reference to computer-based, audio, video and interactive technologies. Three projects investigated learning in the studio classroom and focussed on reflective and creative practice in dance enhanced by the application of technologies. They considered how the embedded use of technology could be researched to improve practice in the teaching and learning of the Alexander Technique, improvisation, and interactive practice in choreography using the software /sadora. The projects involved second and third year undergraduate dance students. It will be seen in the following account and analysis of the three projects that there are considerations that lead from one to another. All three consider the question of the use of technology. The first project looks at the dance student in a movement-based studio setting with a focus on how they learn individually and together. The second project considers students learning together in a studio setting where improvisation is the focus. Finally, the third project considers the future for dance and other students by starting from a consideration of the possibilities of the latest technology. The mediation through technology becomes greater from the first project to the third. 
The application of the Alexander Technique allows students to develop skills in observing themselves and their habitual ways of moving. It is these kinds of skills, which, in the second project, are used within improvisation classes. By applying them, students are able to focus on their habitual ways of creating work and thus develop more conscious and innovative approaches to constructing their improvisations. In the final project, these skills of observing, and of consciously reflecting on process, are applied to choreography developed through an interactive, real-time, digital interface. Here an ability to recognise and inhibit habitual patterns of working allows students to move beyond merely applying superficial digitised effects to conventional choreography. It enables them to embrace new, unforeseen possibilities arising from using technology as an integral part of the creative process. Technology thus operates in the first two projects as a means to enable students to learn to focus more deeply and effectively on observation. In the second and third projects, its integration within improvisation, and the choreographic process, becomes a means for a radical rethinking of what these processes might be.

The pedagogic research that informed this paper has been undertaken under the aegis of the Centre for Excellence in Performance Arts (CEPA) at De Montfort University (DMU), Leicester, UK. CEPA researches approaches to teaching dance, drama and music technology, and explores learning across these creative disciplines and through encounters between them. CEPA's dance 
research develops previous work on reflective practice, in particular. The Centre's strategy brings together researchers and teachers to work on projects in a systematic and co-ordinated way. Pedagogic research projects in dance, drama, and music started in 2005 . The projects referred to in this article were undertaken between October 2005 and July 2007. The four researchers have worked together over two years. Their pedagogic research has developed out of a BA (Hons) Dance programme on which they all teach. They have team taught together for a number of years and have a detailed understanding of each other's teaching. They have discussed their research aims, methods and practices and, through this paper, have explored the broader implications of their findings. The projects involved a total of 175 undergraduate students studying BA Dance at years two and three as part of both single and joint honours degree courses. All second year students were involved in at least one of the projects. A number of students were involved in all three projects.

Both the students and staff worked together. The second year students, in particular, found that they were engaging with research in a number of settings. This helped build a research culture amongst the students - the sort of learning environment encouraged by Jenkins and Healey in their recent work on linking teaching and research in higher education (2007).

\section{Research context}

There have been major developments in the areas of research into pedagogy 
and technology in the last decade, notably Laurillard's pioneering work on the use of learning technologies (2002). Jenkins and Healey have made a sustained and significant case for evidence-based relationships between research, on the one hand, and learning and teaching on the other $(2006,2007)$. They have argued that research / teaching interactions be informed by both sides of that relationship. The researchers in the dance projects discussed have drawn on their example. The CEPA context has been used to pioneer research methodologies that begin from learning and teaching questions in the studio as well as drawing on research to improve pedagogy. The researchers see the relationship as a two way, symbiotic one.

Recently, there has been considerable discussion of the relationships between pedagogy, research and technologies, for instance, in the journal Technology, Pedagogy and Education. McDougall and Jones considered the broad question of research and ICT (information and communications technology). They concluded by making a plea for a greater consideration of pedagogy and technologies that use the theoretical bases of learning and teaching research. Talking about research in ICT in education, they say that:

since the most important role for this research is to contribute to understanding of the processes of learning and teaching, the theoretical frameworks used in mainstream education research are appropriate underpinnings for research in the sub-discipline as well.... Research questions investigating issues of learning and teaching are needed for quality research that will advance knowledge and inform improved practice (2007, 359). 
We aim to consider the relationships between research into dance learning and technology by drawing on theories of learning and teaching.

Within dance there has been, recently and variously, research into the relationships between dance and technology, improvisation and choreography, learning, reflective practice, and creative practice. The field within which we are working is an extensive one ${ }^{i}$. Bannon's recent article on creative practice asks for an opening up of a methodological discourse. The experience of engaging in creative research practice, she observed:

can at times be characterized as chaotic and ambiguous but, ultimately, the time taken to dwell in the possibilities that research presents through the manipulation of the materials and ideas gives a coherence and validity to both process and product $(2004,39)$.

The four researchers have looked at dance, research, learning and teaching and technologies. This current paper deliberately considers what arises when these disciplinary discourses are engaged with through practice. The research questions that arose from our pedagogic practice in the studio and from research into learning technologies formed a basis for the three projects. The questions are: How can dance students' ability to change be facilitated by the enhancement of critical observational skills? How can dance students be encouraged to focus on and reflect on the process of dance practice? How might interactive technologies enhance choreography? One question was common to all projects - how can mediation through technology enhance student learning? 
The three projects.

\section{The application of embedded technology to improve the teaching and learning of The Alexander Technique for dancers (Michael Huxley and Martin Leach).}

\section{Description}

This project was embedded in two core modules of a BA Dance programme.

Students on the programme study the application of the Alexander Technique to dance through the three years of their course. The research focussed on enhancement of the students' peer learning. It developed autonomous critical observation in a structured way, developed techniques of reflection and documented changes in practice using digital video and photography for both students and staff involved. Sessions combined small group work in existing module seminars with additional 'drop-in' sessions for volunteer groups. The practical seminars were fifty minutes long and involved up to twenty-four students; the drop-in sessions were two hours long with a similar sized group. Students recorded selected activities using digital video, downloading the material onto laptops where the activities could be reviewed using iMovie $H D$ and QuickTime software. As an extension and practical application of the Alexander Technique to real-life problems, second year students focussed on their own manner of engagement in performance using digital media for a detailed critical analysis of their dancing. Similarly, third year students applied the Technique to focus on problems of habitual reactivity in creativity and rehearsal in their own performance projects. 


\section{Analysis}

Despite the ubiquitous use of video in higher education there is not an extensive literature on its learning and teaching implications. Laurillard's (2002) Rethinking University Teaching, which has helped define the field of learning technologies, discusses the pedagogical implications of using audiovisual media. She begins with the students, and asks what they need as learners from learning technologies. Teaching, she proposes, 'is a rhetorical activity: it mediates learning, allowing students to acquire knowledge of someone else's way of experiencing the world' $(2002,24)$. Having analysed the learning situation with technology in mind, she lays out an analysis of a comprehensive range of media including those described as narrative, interactive, adaptive, communicative and productive: she identifies learning activities needed by the student and then the forms of media that are most amenable $(2002,191)$.

The Association for Learning Technology's Introduction to Learning Technology within Tertiary Education in the UK (Seale and Rius-Riu 2001) identifies the encouragement of peer tutoring and peer learning as one of the advantages of computer mediated communication $(2001,14)$. The project described here began with a specific learning and teaching issue - the use of peer observation and reflection in dance - and research into the possibilities opened up by the use of technologies derived from that. In Laurillard's terms, the learning activities included attending, apprehending, experiencing, discriminating, articulating, challenging perceptions, experimenting, relating experience to 
theory, investigating, analysing, reflecting on experience, relating theory to practice and synthesizing $(2002,191)$.

Students and professional dancers spend considerable time informally observing themselves and each other. Although some recent dance research refers to observation (e.g. Butterworth 2004), there is considerable scope for more research into observation in dance as a learning practice. Much has been written about reflective observation following Kolb's model of experiential learning (1984), but the emphasis is often on reflection rather than observation. Little has been written about student peer observation in the wider literature. Interestingly, observation rarely figures as a methodology, except in peer assessmenti. Perhaps this is not surprising, as few subjects need their students to observe themselves in practice, dance, of course, being an exception. However, there has been a good deal of discussion recently about peer learning and the arts (e.g. Parnell 2001 on the value of peer discussion when working with groups). In dance, peer learning is touched on in some recent research (e.g. Popat 2002).

Boud, Cohen and Sampson (2001) give a comprehensive account of approaches to peer learning, distinguishing between collective, cooperative and collaborative approaches $(2001,6-7)$. They identify key features of peer learning $(1999,2001)$ and present a model where staff presence is minimal, referring to learning in electronic environments when outlining approaches $(2001,142)$. However, their discussion is primarily concerned with comparing face-to-face and 
virtual settings, rather than the use of a face-to-face peer learning situation that is enhanced by an electronic environment. Nevertheless, they stress the importance for peer learning of what they term 'high-quality learning environments' $(2001,174)$.

This project can best be summarised as a collaborative approach to peer learning in dance where the learning community includes the teaching / researching staff and where peer observation is foregrounded and enhanced by the use of technologies.

When a student arrives at university, they inevitably bring their own personal experience. This experience will necessarily inform everything that they come into contact with, including their learning. We have found that problems can arise in a student's experience of learning due to the extent that their previous experience inflects their present behaviour. Most behaviour is learned and much of that learned behaviour is no longer consciously directed. For the purposes of this project such learned and non-consciously directed behaviour is identified and termed, following F. M. Alexander's use of the term, habit. Habit defined in this way - as something we do that we no longer consciously direct - has radical implications for learning ${ }^{\text {iii. }}$ Looked at from this perspective, education seems to require strategies for dealing with the problem of habitual behaviour. 
One way of addressing the problem of habitual behaviour that has been developed with DMU students is a particular form of peer learning in which students use an analytical and conceptual framework derived from Alexander's Technique. ${ }^{i v}$ The Alexander Technique is used both as a technique of observation and a technique of change, the former being a necessary part of the latter.

During their first year, students are introduced to Alexander's concepts of use and psychophysical unity (as well as that of habit already mentioned). Use, here, may be said to be the way we engage ourselves in activity. This use is always informed by prior experience and conception and so is never purely physical or psychological - as is often implied in tacitly dualist perspectives. Psychophysical use is, simply, a reconceptualisation of learned behaviour and, as already mentioned, has a tendency to become habitual. Students work practically with these concepts and learn to recognise and observe the effects of habitual use. These effects are observable as a particular pattern caused by unnecessary muscular effort that produces a characteristic distortion of the anatomical framework. With experience, students learn to recognise and interpret the components of this characteristic pattern. Following this observation and recognition, the Alexander Technique allows students to undo this pattern in themselves via a targeted self-relaxation of unnecessary muscular effort. Peer observation is used as a means to enhance this self-observation, which becomes part of a conscious strategy for students to recognise and deal with problems 
arising from habitual behaviour. One of the aims of this project was to use digital visual media to enhance these techniques of observation.

Videotaping has been available to dance students and teachers for decades. This project included research into how students can make use of the latest simple digital video technologies in a readily accessible way. Some of the students participating had used high-end hardware, including professional editing suites, and software, such as Final Cut Pro, to make dance videos. Others had no experience. User-friendly fast hardware and software was chosen so that students could master the process within a short space of time, and then spend their time on observation. Most of the students had used simple recording and playback techniques before as part of the choreographic and rehearsal process. We wanted to give close consideration to the way in which students could be encouraged to observe themselves in much greater detail than had previously been the case. We employed a small number of computers and cameras as a way of trialling a low-budget solution that could be used readily in other classes and institutions.

We used three Apple Macbooks running Mac OSX 10.4 and two mini-DV cameras, with tripods. The laptops were dedicated to the project. We chose Apple's proprietary software, iMovie HD and QuickTime. In the workshop, students collaborated in groups of three or four. This meant that in any session some students could work on the live material, some could record; some could 
observe the results on the laptops. Within a given session (fifty minutes) students could review previous material, set up a new observation, video it, download the material, view it, and burn it onto a CD to take away to look at in their own time. From the researchers' point of view, this meant readying the equipment, ensuring that all the material was downloaded, transferring the files to an external harddrive and then copying the sessions' work back onto each laptop. From the student's point of view, they were able to access all their material all the time. During the project we ran eight practical seminars, during timetabled classes, and a drop-in session, every week. This involved hundreds of gigabytes of files.

In working in their project groups the students began to use video in ways that they had not in other settings. All the students used the capacity of both iMovie $H D$ and QuickTime to play back in slow motion. They observed themselves frame by frame repeatedly and talked to each other about what they saw, identifying any observable elements of the pattern of 'misuse' referred to above. They then set up further recording sessions where they devised tasks to look at movement in considerable detail. They learned to observe themselves more closely and consistently. For instance, students undertook a detailed analysis of the activity of walking using their recordings to consider where the activity was initiated: the head, pelvis, knee or foot. Although they discovered that they were all slightly different in their habitual walking, there was an underlying common pattern of misuse, consisting of an unnecessary side-to-side motion. One group worked on this repeatedly, finding that by paying attention to the poise 
of the head and setting themselves up so that they directed their forward walk from the poised head, they could reduce the unwanted swaying significantly. Another group found that the capacity to look at themselves in fast forward motion was an advantage. They researched proprioception and balance, and recorded the simple act of standing for a period of time. They were able to observe the extent to which they swayed back and forth, and from side to side, more acutely by speeding up their recording. They then worked on improving their balance by paying attention to the poise of the head in relation to improvements in the rest of their postural set. They recorded this in close-up and made direct comparisons with previous recordings.

We found that, after a short introduction, the students would use the camera / laptop / software readily without dwelling on its technical features. Moreover, they began to extend the idea. Some groups wished to capture material outside the studio, to examine how they reacted habitually in everyday situations. They used their cell-phone-cameras to do so, discreetly, and brought back the results to observe in class. The main advantage found was in the rapid transference (digitisation) of video material, affording almost instant access, with variations of angle and speed and stop-frame comparisons that far exceeded unmediated camera playback.

The central aim of the students' work in this area was the facilitation of conscious and constructive personal change and improvement in their 
performance work. One key problem with habitual behaviour is that it is very difficult to change because the individual is unaware that they are directing it. Lack of conscious awareness means that habitual behaviour remains invisible to the subject, at least until after its realisation in activity. (For example, we only become aware of an unwanted verbal mannerism after we've uttered it.) Any form of constructive change is impossible without first bringing about some conscious awareness of the activity in question, especially awareness of the moment in which a formal choice is made to engage in that activity. The individual has to know what it is they do in order to begin any process of change. However, increased awareness of activity is of little use if such awareness is only ever after the activity's initiation (although such a posteriori awareness can be valuable information with which to construct an improved conscious conception of existing activity). The student experience tends to confirm that when seriously engaged with, employment of the Alexander Technique in practice (as described in this paper) facilitates students' changev ${ }^{v}$.

Fundamental to the project was the development and enhancement of students' self-observation as a means of bringing to conscious awareness habitual patterns of misuse to facilitate change. For students to know what they actually do, they need to improve the observation of their behaviour. Since it is not easy for students to observe themselves in isolation, they are encouraged to observe each other as a way of observing themselves. People are built to the same general anatomical and neurological plan and consequently if one student 
looks at another doing something, there is a sense in which they are looking at a version of themselves. Because of the shared anatomical and neurophysiological structures, there will be fundamental similarities in the manner that individuals engage in the same activities. With this understanding, when the students are observing each other, they are not only giving feedback to the person they are observing, but doing so with the added awareness that they should look for similar phenomena in themselves. Consequently, because the students during these sessions are always either observing in the context of having been observed - or being observed in the context of having been the observer - they have a reason to trust what one of their colleagues says, as well as a reason to exercise responsibility when voicing their observations. This system of 'using each other as mirrors'si goes some way towards solving the problem of 'selfhypnotism' and unreliable subjectivity associated with self-observation in real mirrors. It is also conducive to the formation of a student-centred collaborative learning community.

One of the problems with the observation of behaviour is its fleeting nature. Often behavioural phenomena occur so quickly that they have already happened before they can be observed. One way in which this problem is overcome is via repetition, but even so, as is the case with all live performance, each observer is reliant on the traces left in individual memory. There is a further tendency for group discussion and analysis of observations to dissipate when the object under discussion is no longer present. The use of digital technology was 
one means of dealing with these problems to enhance students' experience of peer observation.

In the project, the essential elements of peer observation remained unchanged. The main difference was the use of technology. The intention from the beginning was to enable a sense of ownership over the technology as quickly as possible and also to have a sense of ownership and empowerment over students' recording of themselves. To this end, although the teacher-researchers were there to offer advice, it was the students themselves who chose what to observe and how to record it, and it was they who operated the equipment.

\section{Evaluation}

All 175 students involved in the project were asked to complete module evaluation feedback, which was analysed, and some students were moved to write furtherii. All the material made by the students was captured to hard disc. Having established parameters concerning comparison, speed and close observation, these can now be researched further as the technology develops. For instance, the original iMovie $H D$ that was used allowed individual clips to be considered. The later version that was published after the completion of the project allows for a greater manipulation and comparison of clips, and instant access to specific sections. Thus, in the next phase of the research project we will be able to consider all the parameters above, but in much greater detail, whilst retaining student-friendly, inexpensive, accessible software. 
The students' capturing of their own behaviour via digital video did seem to positively enhance their observation of themselves. This enhanced observation facilitated an improved capacity for students to improve their performance by implementing change in their movement making. The video record made it more effective for tutors to identify features in addition to what the student had seen. Previously, this aspect of the teaching process would involve discussion with the student, feedback from peer observers and a repetition of the movement with the intention of changing it. Here the student was always reliant on their own subjective experience of the moment of performance and feedback from their peer observers. Once the performance of the movement was captured to video, it formed a body of documentary evidence that could be manipulated and analysed in far more detail by the student.

When it came to presenting the results of their projects to the rest of the group, students were able to show selected video clips and screenshots to demonstrate their analysis of their movement problems and the subsequent improvements that they had been able to make. In the space of a ten-minute presentation students were able to share this information with their peers and clearly show the differences that could be made alongside an explanation of how and why the change had been implemented. 


\section{The synthesis of embedded technology and evaluative reflection to improve the teaching and learning of improvisation (Sally Doughty).}

\section{Description}

This project researched the development of critical and reflective skills in students engaged in movement improvisation. It was embedded into a third year single honours undergraduate dance-practice module, and also involved a group of professional practitioners. The project had three main aims: to help students understand and acknowledge processes involved in movement improvisation; to develop their ability to verbally report their decision-making processes; and to use a range of technology to support student learning, namely mini-DV cameras, MP3 players and playback monitors. The integration of new technologies provided students with a means to enhance their processes and maximise their creative potential. They undertook self-reflection and analysis in order to develop a more conscious approach in constructing their improvisations. This project refined and re-examined the researcher's existing methodologies.

\section{Analysis}

Improvisation is central to much contemporary dance making, being used both as a means of generating material in rehearsal and as a performance mode. The complexities of movement improvisation have been acknowledged and published in more recent years (Gere and Albright 2003, De Spain 1997). These texts contribute greatly to the slender literature that promotes improvisation as a conscious, intellectual and non-dualistic form. The term 'slender' is used here as 
a majority of texts that deal with improvisation are designed to be teaching aids, offering exercises and tasks (Blom and Chaplin 2000, Minton 1997). There are very few (De Spain 1997) that actually deal with developing and articulating a more analytical approach to the form.

This pedagogic research project set out to promote a framework that asserts a conscious, reflective and analytical approach to improvisation. De Spain recognises the value in attaining this level of awareness in one's improvisational practices when he writes: 'what is lacking ... is an accompanying theoretical knowledge base, so that improvisers could, if they so desired, take a deeper look into their own processes, both gaining understanding and perhaps enriching their work' $(1997,14)$. The questions 'what I do when I am improvising and why do I do it?' were fundamental to this research.

The project used a range of technologies to support the development of a reflective and analytical framework in the teaching and learning of movement improvisation. The research built upon the findings from an earlier project, which explored the use of video as a tool to enhance students' learning experiences (Doughty and Stevens 2002). Reflective thought and judgment are central to the artistic process and are established features of arts pedagogy. It is what 'the best artists and pupils have always done in relation to their own work' (Cowan 1998, 31). This current project used mini-DV cameras, MP3 players and playback monitors to facilitate students' self-reflection and analysis in the 
development of a more conscious approach to improvising. Technology used as a means of enabling these skills enhances a fundamental premise of improvisation, which is that the creative, developmental process may also be the final product. McDougall and Jones recognise this and note that:

Where with pencil and paper technologies we could generally study only the finished version of studentdeveloped artifacts - essays, art work, musical compositions and so on, the capacity of [technology] to enable recording and saving of stages in the development of an artefact enables collection of data providing much greater insight into the process of its development (2006, 355).

Technology, as used in this project, allowed the student-researcher to articulate, document and reflect upon what De Spain calls 'real-time' decision making processes $(1997,5)$ in order to inform future improvisations.

This project placed emphasis on experiential learning. It focused on the student-improviser as observer and analyst, rather than relying on feedback from those external to the act of improvising. The project employed action research, 'improving the student's practice by developing their capacity for discrimination and judgment in particular complex human situations' (Elliot 1991, 49). The improvement of the students' practice in this 'particular complex human situation' (Elliot 1991, 49) of improvisation was developed through making and analysing video and oral recordings of their work. 
Although this project was focused primarily on third year undergraduate dance students, it also informed work with a group of mature dance artists in July 2007. For this latter event, the researcher co-facilitated a professional level course with Kent De Spain to undertake further research. Findings from this course are considered as part of this paper alongside the work undertaken with the students.

With both groups of participants (students and professionals), the use of the MP3 players proved to be a very useful learning tool. Worn in armbands, they gave each improviser the opportunity to verbally articulate out loud what they were engaged in at any one moment, and have this personal commentary captured in the moment of dancing. This recording of the student's processes provided an archival document in which their artistic choices were made explicit. Other researchers have found this kind of record of activity to be a valuable learning tool for performance students (Hunter 2004, 52).

It has become apparent through this project that the verbal articulation of a decision or physical action is a highly sophisticated and complex act. As Charles Schmidt notes:

It does not appear that we can directly report each step of our reasoning. However, at least for some cognitive tasks we can provide information about 'what we are thinking' by verbally describing what is going through our mind while performing the task (2006). 
And as one student commented 'reporting verbally reminded me how complex the skill of improvisation is...I found it difficult to do both [improvise and report] at once'. Fiona Bannon, when writing about developing a creative methodology (2004) refers to Perkins (1981), who developed the strategy of 'think aloud reports'. The primary aim of these reports is to get participants to express their thoughts during the process of engagement with a task. Employing this strategy to facilitate ease of reporting encouraged a more fruitful and confident verbal response from the participants. Students noted that they tended to become too precious about what they reported, often editing and judging before verbalising, which impeded the accuracy of the reporting. However, one professional commented on how the use of the MP3s enhanced her ability to verbally report on her dancing: 'MP3s - good to get me vocalising, talking in a "safe" place [is] easier than talking out to space or to self'.

Having made the verbal report, the student transcribed it. An example of a transcription is as follows:

I'm running back and forwards across the space at the moment. I'm going to carry on doing this. What I like about it is the fact l've got a breeze in my face. I notice that as I talk about breeze I start to do a hand gesture. As if I'm talking to someone to try and explain myself or clarify what I'm talking about bodily. Running, changing the way that I speak... I was just thinking about the tone of my voice while I talked about adjusting my bra strap and whether it became more natural as it did yesterday when I talked about pedestrian material. I don't think it did. I've got this performative voice again. I really don't know how to just speak normally as I'm doing this... I've started to describe what l'm doing again. I've made a decision not to speak or try not to speak unless I am going to actually talk about a reflection or analysis of 
what it is I'm doing... I'm creating this layering with my hands and my feet, and framing my big toe. I wasn't framing my big toe - that just came out of my mouth and it gave me an idea of what to do. And that's important. That's the first time l've realised that the words happened before the movement. l've got one eye closed. I didn't do that on purpose but l've only just realised that it's there.

Having transcribed their verbal report, the students then used guided reflective writing in order to identify the type of language they used to articulate their decisions and observations. They were guided to identify whether they use, for example, descriptive, analytical or emotional language, and whether they have a propensity for using verbs, images, full sentences, questions or statements in their work. The purpose of this task was not for the students or the facilitator to make a judgment on their patterns of language, but rather for them to notice what their patterns were so that they might begin to develop a more conscious approach to their practice and consciously 'create the conditions in which creativity is more likely to thrive' (Kleiman 2005, 27).

Observations made on the verbal report above include the following:

Most decisions are informed by: sensation / physicality, movement / action, environment, reflection / embodied experience...I do not refer to the following at all: effort, emotion, imagination... conscious awareness of a 'performative voice'. My voice got less 'performative' in terms of tone, but more so in terms of volume. I talk about what 'I want...' to do a lot. I made a decision not to speak unless I was going to make a reflective or analytical comment rather than a descriptive one. 
The student made some incisive observations about her verbal report, which allow her to enter into future improvisations with a greater skills base and understanding about her improvisatory practice.

The use of video recording with playback was introduced as the next stage in the project. Students recorded themselves on video and immediately viewed the recording on playback monitors in situ, in the studio. They undertook guided reflective writings in order to establish some or all of the following: habitual movement patterns, use of the performance space, their relationship to other performers and the structure of their improvisations. Noticing these nuts and bolts of composition helps the improviser to identify decisions made and how these may be manifested in practice. It encourages improvisers to develop greater conscious control over both the form and content in their work in what Emmanuel Levinas terms as an 'original and originary way' $(1996,19)$. Barbara Bolt writes that the term originary 'seems particularly pertinent to creative arts research. It is a way of understanding that derives from, or originates in and of the thing in question. In this case, the "thing" in question is practice. It is understanding that originates in and through practice' (2006). So, through practising and observing, students begin to refine their ability to engage in improvisation in an informed and conscious way. As one of the students reported:

I think the immediacy [of dancing, watching and dancing again] means you can really notice a particular aspect of what you are doing and try to look at that next time you are 
filmed, and then watch it straight away to see if you have achieved what was intended.

The advantage of embedding this kind of reflective practice into studio based work is that it becomes possible, after viewing and reflecting, for improvisers to immediately respond to their findings by undertaking further practical investigations. The revisited improvisation can, of course, be recorded again, played back and revisited further so that the improvisers engage in an ongoing cycle of experiential learning.

Watching the video recording as a group allowed input from peers so that students can actively engage in peer and self-observation. However, as one student observed: 'although feedback is useful from group members, actually seeing [myself] is a great advantage in being able to develop not just [my] awareness, but my self-analytical skills too'.

Working with the MP3 and video together allowed the students' reporting and dancing to be recorded simultaneously. This provided a watertight archive of their spontaneous decision-making processes and physical response. After simultaneously listening to and watching the recordings, they undertook further guided reflections in order to identify, for example, whether their verbal report had any correlation to the physical act, and whether they had habitual movement responses to a range of different verbal reports. Observations made include:

Sometimes I spoke before I moved. I experienced a desire to stop moving and just speak... awareness of environment led to a consideration of architecture and modernity... I became 
very conscious of my habitual tendencies, which were:

movement mainly involves arms and legs or hands and feet.

I tried to stop this but then became able to reinvestigate this and discovered that it was 'how' I moved those parts of my body that was habitual. The improvisation included a consideration of 'layered' movement material. These reflections then extended to consider the layers of the floor (which involved the use of imagination). This then evolved to the layers of myself - skin, muscles, bones...

The purpose, again, is not to achieve any direct / indirect correlation between the report and practice, but to notice what their patterns of behaviour are. Once this noticing has taken place, improvisers are more equipped to make conscious decisions about what they do and why they do it and therefore maximise their creative potential.

\section{Evaluation}

The combination of the MP3 work and video recording / playback proved to be an invaluable approach in developing the participants' understanding of the processes involved in movement improvisation. As one student noted: 'the two work quite well together as a learning tool. There's a cumulative effect of starting with the MP3 and adding the videotaping which made an inherent shift in my understanding of the benefits of each.'

This research project demonstrated that embedding the use of a range of technologies in a teaching and learning environment positively enhanced both students' and professionals' ability to engage in improvisation in a meaningful way. Using oral and video recordings with immediate playback provided 
strategies for self-reflection and analysis of their practice. As feedback from one student states, 'I am more aware of what I do and why'. Technology, although a fundamental part of the project, facilitated rather than dictated the thrust of the research. It provided students with the means to notice and analyse decisions they made, which in turn developed greater understanding, acknowledgment and control of the complex processes involved in movement improvisation.

\section{Interactive practice using the software Isadora (Kerry Francksen). Description}

This project researched the use of an interactive graphic programming environment called Isadora (designed by Mark Coniglioviii) to enable students from a variety of disciplines to engage with real-time interactive media in a creative context. Isadora is:

A real-time software tool to support the creation of interactive live performance work for installation or stage. Programmed to manipulate digital video, the Isadora software interface is designed to be easier to use than other similar real-time software tools (deLahunta 2005, 31).

The project involved students making performance work by integrating live and mediated images in real-time. It lasted for a week and took place outside of the teaching term in the summer break, bringing together students from dance, music technology and photography and video. The premise of the project was for the technology to support shifting an idea forwards rather than for the technology to drive the compositional elements of the idea. Povall suggests, one should 'be absorbed in the performance, not in the technology or the tricks, or the gee-whiz 
effects' $(2001,457)$. This idea provided the students with a focus, with an emphasis on using the technology as an integral part of their artistic process and not as a means of generating effects.

\section{Analysis}

The project researched how new technology might figure as an integral agent in the creative process rather than merely using it as an external tool for postproduction and after effects (Popat \& Palmer 2005). By setting up the project with a clear focus on creative process and not on the production of a final product the students seemed to maximise their understanding of using interactive technology in the moment as a creative counterpart, rather than as a box of tricks. Through this it also became very clear that their joint experience of using Isadora in realtime shifted their ideas away from a structural approach where 'the possible range of bodily actions, dynamic and spatial elements...tend to organize movements in a distinctive manner, that is, to link them together in particular ways' (Adshead 1988, 43) to one where the integration of mediated images with those in real time enabled students to take less traditional approaches in building choreography.

Although students were engaged in the process of formulating ideas and organizing them, they were much more interested in creating a dialogue in realtime between all of the compositional elements as they experienced them in interactive space. This was seen as distinctly different from their usual 
experience of directing dancers through the choreographic process of drafting and re-drafting movement into a finished piece. The onus was therefore not on having to work towards this final outcome, which one of the students described as 'forcing them to make decisions more quickly' resulting in 'many ideas being thrown away'. They enjoyed instead the freedom of being able to generate an idea and then continue exploring past the point where they would normally start to make selective decisions. Students attributed this productive freedom to the possibilities created in real-time. As a result they were continually redefining their understanding of the design elements in the work. As the week progressed, the focus shifted from making a final piece to generating situations and interactive environments, which could be shared between them and any potential audience.

The creative process was considered from a position of 'creativity arising from interactions with machines' (Pachet 2006, 353/354). Key here is the possibility afforded for the machines (in this case Isadora software) to provide real-time interaction. Rather than the technology being applied after the choreography had been finished, it became integral to the generation and formulation of ideas. The students saw this as far more fluid and flexible in terms of their creative process.

From a choreographic perspective this meant that the students were able to investigate, not only what it meant for them as performers and creators to be part of an interactive environment, but also how an audience might experience this. This shifted their habitual notion of creating work for a more conventional 
setting - such as a proscenium arch theatre space for example - to one, which considers the performance space as an interactive environment. This then provides opportunities for a more immersive experience for an audience. This is the type of experience that Hawksley and Biggs have discussed $(2006,136)$.

Moreover, the students' engagement in the choreographic and compositional process seemed to manifest itself as a potential experience for both themselves and for those viewing the work rather than creating a piece of choreography that has been generated from a deferred position of directing ideas from the outside. Thus through their utilization of Isadora and respective media (including live, video, projection, real-time manipulation and soundscapes) the formation of ideas moved away from their usual understanding of what it means to compose to an experience of 'embodied... physical interaction' (Hawksley and Biggs 2006,136). By having to deal with a whole new set of interesting problems, such as the aesthetic considerations that arise directly from being in an interactive environment, students were developing and re-defining how they composed their ideas in an experiential way. One student said that 'overcoming the challenges of the different aesthetic principles or preferences when using interactive technology, I think is going to be something we need to look at without compromising ideas'.

The very fact that they were asked to consider interactivity as part of their creative process meant that the methodologies and strategies employed were far more concerned with how they might experience the creative idea or concept. 
Boud, Cohen and Walker describe this 'experience [as] a meaningful encounter. It is not just an observation, a passive undergoing of something, but an active engagement with the environment, of which the learner is an important part' $(1993,6)$. The key point here is the learner as an integral part of the active engagement in the work in an immediate sense. For example, one group of students used Isadora to track the dancers moving in the space through a live video feed. This was then projected behind them in the performance space with a slight delay so they could continually witness the movements they had just carried out and react to them accordingly. These movements were then overlaid with pre-recorded images, to provide the dancers with another stimulus to react to. In addition, the dancers were also able to control elements of the sound, such as the pitch or length of a sound, by where they placed themselves in relation to the camera tracking their movements. Their engagement was not only multilayered but became fully focused on how they might manipulate what they saw themselves doing in relation to the pre-recorded images and in order to compose the sound.

What becomes apparent is that by engaging in an experience, which is concerned with real-time manipulation of events in time and space, the students were able to draw on their current skill base. Furthermore, they had to redefine and move away from an idea that composition is solely concerned with creating a completed presentation, which has been clearly structured through continual developments over time. They had to consider how to utilize their skills in a more 
immediate and visceral sense. For example, both dancers and musicians used their skills in improvisation in order to move their ideas forwards. Their approach became governed by how this worked in relation to an occupied space (not just the live dancer but the mediated dancer, virtual dancer, image, light, sound, and crucially live feedback loops within the software etc.). As such they had to deal with other conceptual ideas, such as dancing with oneself. Any notions they might have of structuring and composing various performative elements therefore needed to take into account a plethora of other ideas taking place in the same space. Whilst this does not suggest that they were not accustomed to dealing with such approaches and methods in the context of their undergraduate courses, it does highlight a shift, particularly for those students studying dance, into a situation, which requires them to make use of their embodied experiences. What Pachet describes in relation to musical creativity is also relevant for the dancers' experience:

By interaction we mean the real-time relationship between a human user engaged in a musical activity and a program. Interactions are not bidirectional in our context, and we are strictly interested: in the objective output of the coupled user + system and the psychological impact on the user. In particular, the creativity observed is to be assessed with regard to the normal activity of the user without the program $(2006,353)$.

In dealing directly with the effects that the technology was having on their ideas, dance students commented on how their 'normal' activity 'without the program' was no longer a subconscious process but one that highlighted how they could utilize their skills and configure a new means of dealing with form and aesthetic decisions within an interactive environment. This, in turn, was seen as an open-ended process of continually developing an idea rather than finishing 
with a highly choreographed piece. This approach was seen as different from that of their everyday experiences as part of their undergraduate study of choreography and highlighted a shift for them both creatively and aesthetically.

Those students studying music technology had more confidence when using the software and took the lead in designing using the software's modules. Dance students found the act of designing far more challenging. However, all of the students were able to negotiate the interface and feedback from the students highlighted the benefits of having to use the technology as part of their creative process. Furthermore, the very fact that they were working with musicians and videographers enabled them to access a working knowledge of the software by learning from their peers. The dance students found this an extremely positive experience. The musicians enjoyed being part of the physical space rather than just being left to do the designing. This shared interactive experience meant that they were learning not only about their own aesthetic choices and notions of composition, but learning by engaging in the process with others from different disciplines. This highlighted other methodologies they had not thought of before. The technology clearly became part of this process, and their experience of dealing with the nature of the technology was integral to their learning.

By concentrating on the shared experience and by engaging in an interactive environment, students have been able to question the very nature of interaction, in terms of both the collaborative and creative process. Through this 
experience, their ideas and methods have embraced an approach that Sullivan has identified:

A way to think about the complex visual and virtual world around us is to consider the enormous range of ways that we use technology to represent things.... It is important, however, to realize that being surrounded by a mostly fake environment is not such a bad thing, as long as there is an awareness of how these multiple realities can be accessed, appraised, and used for purposes of creating new understandings of what is around us (Sullivan 2007, 1184).

\section{Evaluation}

Through this project, students became more familiar with how they might understand a complex environment. The key point is that the project put them into a position of using the technology in a way that was implicit within this understanding, particularly from the point of view of choreographing and composing. One student wrote in her evaluation 'our initial ideas focused on projection, surface, texture, depth, perception and motion and we simply used Isadora to project our video footage'. However, 'as the week progressed our ideas began to evolve and we began to experiment with Isadora and what possibilities it could provide for our ideas. In the end we developed naturally from using Isadora as a facilitating device to Isadora being a key creative component to our ideas'. More evidence of this comes from another student who states 'we did not really use Isadora as an "effect machine" but we were more interested in the video and live work and how these two came together in space.' Through discussions, students seemed far more interested in how all of the elements could coalesce in space and how the different compositional elements could be 
considered in real-time rather than how they might generate effects through the software.

As a result of experiencing /sadora, students were able to engage with the process of composition in an intelligent and articulate way, most specifically in terms of their treatment of live, mediated and interactive spaces. It would seem that:

Digital technology is not a thing you merely buy and install, it is a place to create and occupy. This has profound educational implications. The digital world is a place that can be blandly accepted for what it is - in which case an individual will be a passive vessel into which anything and everything can be poured. Conversely, digital technology can be a place of imagination, for reinvention, and creativity. In this case, what is fake is made real as long as the individual is able to access it and remake it (Sullivan 2007, 1184).

Furthermore, the integration of technological resources, particularly as a compositional device, must involve far more than just learning how to use the interface. It must concentrate on how the teaching and learning of such technology can be absorbed and developed as part of the creative process. It is also worth noting that whilst Isadora was considered a useful tool, it became clear that it is only one means of interacting with new technologies amongst others on the market. It should therefore be treated as what Birringer calls 'a digitally enhanced space or "operating system" that triggers responses and feedback' $(2003 / 2004,93)$. Technologies such as motion capture systems, the use of sensors and other interactive environments provide means of engaging in this type of work. 
The project has shown that integration must come from a clear insight into how the technology can further develop the creative process. It shows the need for the role of technology to be clearly identified within the creative process. The integrity of the idea and the ability for students to push their own boundaries and intellectual perceptions is based on both an understanding of their own working practices and methodologies and the intellectual and philosophical debates that underpin how the technology can enhance the creative process.

\section{Conclusion}

The projects examined in this article consider different, but related, areas of the undergraduate dance curriculum: the research undertaken and discussed has revealed outcomes that go beyond the individual project. What ties them all together is a common approach informed by, and based in, teaching and learning on the one hand, and its enhancement through technology on the other. All three projects have shown how technology can enhance dance education when based on a researched investigation into what students need for their learning. It is exciting to report that the approach advocated here applies equally, in dance, to what might be called 'fundamentals' as to cutting edge artistic exploration.

The learning environment created by such an approach to technology can become a starting point for further and innovative developments. Undergraduate 
dance courses differ significantly from each other. The authors would not suggest that the curriculum content that their researches are based on - Alexander Technique, improvisation, and interactivity in choreography - in themselves should be replicated elsewhere. However, the application of the approach described here should be encouraged. That is to say, one that takes pedagogic research as a basis for exploring technological possibilities so as to ensure that they are embedded, rather than merely added on. There are considerable advantages to a research team approach, where methods and theories are shared and developed, for both researchers and students. The research that has been undertaken here has opened up a wider discourse about dance, learning and teaching, and technology that promises much for the future. 


\section{References}

Adshead, J., Briginshaw, V.A., Hodgens, P., Huxley, M. 1988. Dance analysis: theory and practice. London: Dance Books.

Alexander, F.M. 1996. Man’s supreme inheritance. London: Mouritz.

—. 2000. The universal constant in living. London: Mouritz.

- 2001. The use of the self: its conscious direction in relation to diagnosis, functioning and the control of reaction. London: Orion.

- 2004. Constructive conscious control of the individual. London: Mouritz.

Bannon, F. 2004. Towards creative practice in research in dance education. Research in Dance Education 5(1): 25-43.

Birringer, J. 2003/04. Dance and interactivity. Dance Research Journal Winter 2003 and Summer 2004 35/2 36/1: 88-111.

Blom, L.A. and Chaplin, L.T. 2000. The moment of movement: dance improvisation. London: Dance Books.

Bolt, B. 2006. Materializing pedagogies. Working Papers in Art and Design. University of Hertfordshire.

http://sitem.herts.ac.uk/artdes_research/papers/wpades/vol4/bbabs.html

Boud, D., Cohen, R. and Sampson, J. 1999. Peer learning and assessment. Assessment and Evaluation in Higher Education 24(4): 413-426.

- 2001. Peer learning in higher education: learning from and with each other. London: Kogan Page.

Boud, D., Cohen, R. and Walker, D. (eds.) 1993. Using experience for learning. Buckingham: The Society for Research into Higher Education \& Open University Press.

Bresler, L. 2007. International handbook of research in arts education. Dordrecht: Springer.

Broadhurst, S. 2006. An aesthetic and neuroesthetic approach to virtuality and embodiment. Performance Research 11(4): 137-147.

Butterworth, J. 2004. Teaching choreography in higher education: a process continuum model. Research in Dance Education 5(1): 45-67. 
Cowan, J. 1998. On becoming an innovative university teacher. Reflection in action. Buckingham: Society for Research into Higher education and Open University Press.

deLahunta, S. 2005. Isadora 'almost out of beta': tracing the development of a new software tool for performing artists. International Journal of Performance Arts and Digital Media 1.1: 31-46.

Deliege, I. and Wiggins, G.A. 2006. Musical creativity - Multidisciplinary research in theory and practice. London: Psychology Press.

De Spain, K. 1997. Solo movement improvisation: constructing understanding through lived somatic experience. Philadelphia: Temple University.

- 2000. Dance and technology: a pas de deux for post-humans. Dance Research Journal Summer 2000: 2-17.

Dillon, P., and M. Åhlberg, 2006. Integrativism as a theoretical and organisational framework for e-learning and practitioner research. Technology, Pedagogy and Education 15(1): 7-30.

Door, B. 2003. Towards perfect posture. London: Orion.

Doughty, S., and J. Stevens. 2002. Seeing myself dance: video and reflective learning in dance technique. Paper presented at Finding the Balance Conference, on Dance in Higher and Further education in the $21^{\text {st }}$ Century, June 21-23, in Liverpool John Moore's University.

Elliot, J. 1991. Action research for educational change. Milton Keynes: Open University Press.

Gere, D. and Cooper-Albright, A. (eds). 2003. Taken by surprise: a dance improvisation reader. Middletown, Connecticut: Wesleyan University Press

Hawksley, S. and Biggs, S. 2006. Memory maps in interactive dance environments. International Journal of Performance Arts and Digital Media 2 (2): 123-137.

Hunter, D. 2004. Enriching learning through the evaluation of process. In How am I doing? Valuing and rewarding learning in musical performance in higher education, ed. D. Hunter. 47-60. University of Ulster.

Huxley, M. R., M. Leach, and J. Stevens. 1995a. Breaking down the barrier of habit: an interdisciplinary perspective on the ideas of F.M. Alexander and the theory and practice of dance. Paper presented at Border Tensions: Dance and 
Discourse - Fifth Study of Dance Conference, April 20-23, in University of Surrey.

1995b. The integrity of the whole: the application of the ideas of F.M. Alexander to contemporary dance practice - a reappraisal. Paper presented at IInd International Congress on Dance and Research, July 9-13, in Vrije Universiteit, Brussels.

Jenkins, A., and M. Healey. 2006. Institutional strategies to link teaching and research. Higher Education Academy. http://www.heacademy.ac.uk/assets/York/documents/resources/resourcedatabas e/id585_institutional_strategies_to_link_teaching_and_research.pdf.

Jenkins, A., M. Healey, and R. Zetter. 2007. Linking teaching and research in disciplines and departments. Higher Education Academy. http://escalate.ac.uk/3783.

Kleiman, P. 2005. Beyond the tingle factor; creativity and assessment in higher education. Paper presented at ESRC creative seminar, October 7, in University of Strathclyde.

Kolb, D.A. 1984. Experiential learning: experience as the source of learning and development. Englewood Cliffs, NJ: Prentice Hall.

Laurillard, D. 2002. Rethinking university teaching: a conversational framework for the effective use of educational technology. ( $2^{\text {nd }}$ ed.). London: Routledge.

Lavender, L., and J. Predock-Linnell. 2001. From improvisation to choreography: the critical bridge. Research in Dance Education 2(2): 195-210.

Leach, M., and J. Stevens. 1996. The dancing self: conscious direction of the body in performance: the Alexander Technique in dance performance. Paper presented at, Congress on Research in Dance. The Body in Dance: Modes of Inquiry. Paradigms for Viewing Artistic Work and Scientific Inquiry, November 710, University of North Carolina, Greensboro.

Levinas, E. 1996. Martin Heidegger and Ontology. Diacritics, 26 (1): 11-32.

McDougall, A., and A. Jones. 2007. Theory and history, questions and methodology: current and future issues in research into ICT in education. Technology, Pedagogy and Education 15(3): 353-360.

Minton, S. C. 1997. Choreography : a basic approach using improvisation $\left(2^{\text {nd }}\right.$ ed.). Champaign, Illinois: Human Kinetics. 
Pachet, F. 2006. Creativity studies and musical interaction. In Deliege, I. and Wiggins, G.A. Musical creativity - Multidisciplinary research in theory and practice. London: Psychology Press: 347-358.

Parnell, R. 2001. It's good to talk: managing disjunction through peer discussion. Higher Education Academy. http://cebe.cf.ac.uk/aee/pdfs/parnellr.pdf.

Perkins, D. 1981. The mind's best work. Cambridge, MA: Harvard University Press.

Popat, S. 2001. Interactive dance-making: online creative collaborations. Digital Creativity Vol.12, no.4: 205-214.

2002. The TRIAD Project: using Internet communications to challenge students' understandings of choreography. Research in Dance Education 3(1): 21-34.

Popat, S and Palmer, S. 2005. Creating common ground: dialogues between performance and digital technologies. International Journal of Performance Arts and Digital Media 1 (1): 47-65.

Povall, P. 2001. A little technology is a dangerous thing. In Moving history / dancing cultures: A dance history reader. Eds A. Dils and A. Cooper Albright. 455-458. Middleton, CT: Wesleyan University Press.

Schmidt, C. Cognitive Architecture. Rutgers, The State University of New Jersey. www.rci.rutgers.edu/ cfs/472 html/CogArch/Protocol.html.

Seale, J., and M. Rius-Riu. 2001. An introduction to learning technology within tertiary education in the UK. Oxford Brookes University, Association for Learning Technology.

Sullivan, G. 2007. Creativity as research practice in the visual arts. In Bresler, L. ed. International handbook of research in arts education. Dordrecht: Springer: 1181-1194.

\footnotetext{
i Developed by, amongst others, Bannon (2004), Birringer (2003/04), Broadhurst (2006), Butterworth (2004), De Spain (2000), deLahunta (2005), Doughty and Stevens (2002), Lavender and Predock-Linnell (2001), Popat (2001, 2002).

ii Most of the discussion and research concerns peer observation of lecturers in peer review and appraisal.
} 
iii This radical conception of habit is based on the ideas of F.M. Alexander expounded in his four books Man's Supreme Inheritance (1910/1945/1996), Constructive Conscious Control of the Individual (1923/2004), The Use of the Self (1932/2001) and The Universal Constant in Living (1941/2000).

iv The approach has been outlined in papers by Huxley, Leach and Stevens (1995a and 1995b) and Leach and Stevens (1996).

${ }^{v}$ One student reflected that what the project had given her was 'primarily the ability to implement changes in my, life whether inside or outside the dance studio, by acknowledging the problem of habit and then trying to address it.'

${ }^{\mathrm{vi}}$ Brian Door developed this system of peer observation in his training of teachers of the Alexander Technique where he coined the term 'using each other as mirrors'. He directed an Alexander Technique training course from 1979 to 2004 during which time it became the training course of the Professional Association of Alexander Teachers. It was Brian Door who first introduced the Technique at Leicester Polytechnic (forerunner of DMU) in 1984 and his book Towards Perfect Posture has been used as a practical core text since its publication in 2003.

vii One of them summed up the contribution of the project as follows: "The use of new technologies is beneficial in a way that it has enabled me as a student to critically evaluate mine and other people's behaviour better. We could observe each other not only in real time / the moment of action but look back on our behaviour at a later stage and compare each other's behaviour."

viii Mark Coniglio is an artist who crosses the disciplines of music, dance, theatre and interactive media. Dubbed an 'interactive performance pioneer' by the New York Times, his work has been performed nationally and internationally primarily with Troika Ranch, a New York City-based performance company committed to creating multidisciplinary works of which he is co-director with choreographer Dawn Stoppiello.' (deLahunta 2005:32) Visit www.troikatronix.com for further information. 